\title{
Evaluating walking promotion policies with regard to mobility representations, appropriations and practices in public space
}

\author{
S. Lavadinho \\ Observatory of Mobility, Geneva University, Switzerland
}

\begin{abstract}
To effectively encourage pedestrian use, urban planning must meet pedestrian needs. But how do public policies that support human-powered mobility translate into real-life practices? Which built environment factors encourage users to adopt existing pedestrian routes and integrate them in their daily travel? This research reveals pedestrian practices and the way they connect to other daily activities. It gives suggestions for a targeted policy of promotion of pedestrian routes in agreement with different user profiles. It elucidates the mechanisms of appropriation of public spaces that influence walking choices, and which urban planning elements are most conducive of walking behaviour. The research design followed a two-step process: first an onsite evaluation of the objective characteristics of three of the nine walking routes currently proposed by the Geneva Pedestrian Masterplan, followed by an onsite quantitative survey that described users' walking behavior and their judgements on the adequacy of these routes to their needs, desires and daily practices.
\end{abstract}

Keywords: urban planning, walking, public space, evaluation, human-powered mobility, promotion policies, pedestrian behaviour.

\section{Is walking still part of our mobile world?}

Though we do seem to live in a very mobile world, our first request goes not towards mobility per se, but rather the wild range of activities being mobile authorizes. Placed within a dense urban tissue, people may not request the car as such, and might even be inclined to refrain from using it. What they ask for is a simple, flexible, fast and effective means of transportation. While for the time being it is undeniable that individual motorised traffic is still seen as the best 
way to satisfy mobility needs, and may indeed be quite adapted to many daily life situations, this is but the result of our current mobility referential grids. We tend to forget that the automobile appears quite urban-friendly essentially because over the last forty years cities invested titanic means and gigantic sums in becoming car-friendly. Thus when talking about walk-friendly cities today, we are to ask ourselves, as citizens as much as researchers, planners and decision makers, how much money and effort do we want to invest on making them walkable? Though a single means of transport may have framed a certain type of urban network up until now, one could just as easily imagine, and it is already starting to happen in several European cities, to unravel this network back into a raw material from which other transport options may emerge. Future urban mobility trends very much depend on which referential grid we are deciding to adopt right now and which urban solutions are forthcoming to connect us and satisfy our needs and desires in the next decades.

\section{Can walking be sexier than driving?}

The multiplicity of activities and their scattered functional space distribution tend to fragment urban fabric, thus impoverishing accessibility of most other ways to move about besides the car. As a consequence we tend to think only seldom of human-powered mobility as a viable alternative, be it in terms of speed or in terms of freedom to choose from a wealth of possibilities of connecting various places by surer, quieter and often more direct routes than by car. However, on relatively short distances, walking and bicycling may actually reveal themselves very competitive means of transport precisely because they are individual means of transport. As such, unlike public transport, they are not constrained by predetermined schedules and routes, thus allowing a substantial degree of freedom in planning door-to-door displacements. However, to bring about change in current walking practices, the planning of walking facilities into a comprehensive and effective walking network must not be based solely on offer-based presumptions of what is feasible. It should instead strive to meet the demand by trying to gather knowledge on what is desirable. That means learning more about existing needs and drawing inspiration from existing motivations. To effectively raise the current modal split in favour of human-powered mobility, the act of walking must be made much more attractive than it is nowadays. Instruments and arguments, both material and immaterial, to convince people to walk more are thus being developed by most European cities to raise walking routes' attractiveness. The Pedestrian Masterplan (http://www.villege.ch/geneve/plan-pietons/index.html) developed by the Town of Geneva since 1995 fits in this current trend.

\section{The Geneva Pedestrian Masterplan}

Adopted by the City council in 2001 and approved by the Geneva State Authorities in 2004, the Pedestrian Masterplan is the result of a longer process that started out in 1995 following the early signature of the Aalborg Charter that 
had just been launched by a great number of European cities in the wake of the 1992 Rio conference. The first of the five main axes developed within the scope of the Masterplan is devoted to walking promotion: it aims at encouraging walking by developing and promoting walking routes within and between districts. In addition, the Town of Geneva chose to reinforce the visibility of the Masterplan by editing a series of maps retracing the developed walking routes. The Town has conceived two lines of action: to create walking routes and to promote a coherent network that connects the city with its suburbs and adjacent municipalities, which bypasses administrative borders to focus on the real walking practices.

\section{How do we know it's working? People actually walk there}

The present paper evaluates this walking promotion policy near completion, as it has spanned now for almost all of its planned ten year-cycle. To learn more about the Pedestrian Masterplan acceptance we carried out during spring 2004 a survey of 619 walkers at 12 selected spots on three different walking routes throughout the city, and tried to answer the following questions: What kind of people walk? Where, when, and why do they walk? How do they combine walking with their other daily routines? How are the Town's efforts to promote walking perceived? How well do people know and use the published maps? How do the proposed walking routes influence walking patterns and mobility behaviour choices? Which built environment factors are most important when people engage in the dynamics of walking, setting into motion a fourfold complex process involving perceptions, representations, appropriations and practices of public space?

\section{The walker's profile}

\subsection{What do people walk for?}

People tend to walk mainly for leisure purposes $(76 \%)$, either by themselves $(22.5 \%)$, with their dog $(19 \%)$ or with their children or grand-children $(10 \%)$. Leisure motives are consistently the most mentioned regardless of the age group, though the tendency does increase with age, from $50 \%$ of teenagers to $75 \%$ of seniors. Taking time off to relax within a public space, namely sitting on benches, during lunch breaks or after work, accounts for $8 \%$ of users' motives. Sports $(5.5 \%)$ and tourism $(2.1 \%)$ seem to play only a minor part on leisure motives. On the other hand, transit motives gather a third of all users $(33 \%)$, mostly on their way to other leisure activities (9\%), school or work $(7 \%)$ and shopping (7\%). People with no vehicle at their disposal are twice more likely to walk to work ( $25 \%$ vs. $12 \%)$. Other transit motives include socialising practices such as eating out, meeting or visiting friends and accompanying children to their activities. Most people walk for only a relatively short time, remaining within the vicinity of their home or office. Men walk more to go to work $(22 \%$ vs. $14 \%$ ) and seem more inclined to mention walking as a physical activity 
beneficial for their health (11\% vs. 7\%), whereas women walk slightly more for leisure (66\% vs. $62 \%$ ) and overwhelmingly more to accompany their children and grandchildren (of a total of 24 people quoting this reason, 23 were women; this motive thus represents a share of $11 \%$ of all the motives quoted by women, vs. less than $1 \%$ of those quoted by men).

\subsection{What makes people walk?}

The most frequent motivation is to improve health (21\% of all answers by $51 \%$ of respondents). The older the people, the more sensitive they become to health issues (only $50 \%$ of teenagers mention health vs. $50 \%$ of adults and $75 \%$ of seniors). Interestingly, those with a vehicle at their disposal seem slightly more sensitive to the health benefits of walking (56\% against $49 \%)$. To be out in the open is also quite appreciated (12\% of all answers by $30 \%$ of respondents), and walking is seen as more relaxing (11\% of all answers by $27 \%$ of respondents). The no-stress factor strikes a chord with drivers in particular (29\% vs. $24 \%$ ). Drivers are also twice more likely to walk for the benefit of their children. $23 \%$ of respondents find walking more beautiful. Since a person out of four prefers to walk because it is less stressing and one out of five because it is more beautiful, it proves to be meaningful to continue to develop sure and pleasant walking circuits that enhance pleasure while walking. $20 \%$ of people choose to walk when their destination is rather close. Likewise, $20 \%$ find walking more practical. The younger the people are, the more practical they find walking (a teenager out of four vs. only a senior out of ten). $9 \%$ of people quote speed as a reason to walk, which for a reputedly slow means of transportation is not such a bad result, but age matters greatly in speed evaluation (a young person out of five regards walking as faster, against an adult out of thirteen and only one senior out of a hundred). Stating that walking is for free strikes a chord with $8 \%$ of people who are price-sensitive. Avoiding congestion $(5 \%)$ and parking $(6 \%)$ problems is a motivation for only a relatively scarce number of car drivers, as is avoiding overcrowded buses at peak hours for mass transit users (6\%). Public promotion policies should take into account these motives in order to find the most suitable angle of attack for walking promotion marketing and communication campaigns. Health and wellbeing arguments in particular might be effective, when potential target groups can be effectively reached. We recommend carrying out joint communication campaigns sponsored by both mobility and public health services and adequately target specific parts of the population, essentially older adults and young parents worried by the health of their children. Children do represent a powerful lever, and promoting walking within this target-group would deserve detailed attention, especially since parents tend to use their cars much more than people who do not have children. A child who walks often represents one or more adults who walk too, therefore there might be some interest in promoting walking as a family affair.

\subsection{What other means of transport is used besides walking?}

Firstly we would like to observe that according to our results there is an extremely strong fidelity to the usual means of transportation, weakening 
possibilities of modal split change and posing a great challenge to walking promotion policies. On a more positive note, when users decide to forsake their usual means of transport, they usually do so to the profit of pure walking practices. Fidelity varies according to the means of transport: people are the most faithful to their two wheels and the less faithful to public transport, the car coming somewhere in between. Only 3\% of the users declare walking as their usual means of transportation. Half of the respondents usually recur to public transport, one out of four drives a car and $6 \%$ ride with someone else. As per two-wheel drivers, $16 \%$ are cyclists while $6 \%$ prefer the scooter.

For the particular walk that was surveyed, more than half of the users $(53 \%)$ didn't use any other means of transport. $23 \%$ combined walking with public transport, $13 \%$ with the car and $11 \%$ with the bicycle. Only $2 \%$ used a scooter. Cycling was preferred by men $(13 \%$ vs. $9 \%)$, especially teenagers and young adults ( $17 \%$ vs. $7 \%$ of active adults and only $2 \%$ of seniors), whereas women chose public transport more often $(27 \%$ vs. $18 \%)$, as did teenagers and young adults (31\% vs. $16 \%$ on average for all other age groups). People who don't have a car at their disposal are more likely to just purely walk (56\% vs. 51\%), to use public transport $(30 \%$ vs. $18 \%)$ or cycle $(12 \%$ vs. $9 \%)$. Conversely, people who live in households with two vehicles tend to become people who drive their car more often $(29 \%$, vs. only $12 \%$ of those living in households with just one vehicle). Children-related constraints weigh high on car dependency as a walking complementary mode. People who live with no children cycle more $(12 \%$ vs. $8 \%$ of those who do) and recur to public transport more often (24\% vs. $18 \%)$, whereas those who live with children use their cars much more (19\% vs. $9 \%)$.

\subsection{What urban tissue is preferred?}

People usually enjoy more than one type of urban tissue. Green walking circuits that include parks, natural sites and other green spaces are a definite must: mentioned by $77 \%$ of respondents, they take the largest share of all answers at $38 \%$. Thus a planning policy such as the one applied in Geneva, that strives to link parks and other green sites through walking circuits, does seem to be a good strategy that answers people's needs. Blue walking circuits that follow water courses come second, mentioned by $56 \%$ of respondents with a share of $27 \%$ of all answers. Therefore rehabilitating waterways and converting them to more human-powered mobility uses not only meets environmentally sound criteria and health promotion recommendations through an increase of physical activity, it also allows for renewed waterscapes more in tune with people's expectations. Animated walking circuits that include shopping streets lined with cafes and restaurants come third with a share of $13 \%$ of all answers mentioned by $26 \%$ of respondents, more often than not young people yet single or mature men. Designing better interfaces between commercial venues, services, cafes and restaurants and spaces where people walk and adding porosity to this kind of circuit enhances its qualities. Beyond infrastructure, time issues should be considered, such as opening hours in tune with pedestrian fluxes and increased offer levels during high seasons. Quiet and relaxed walking circuits along residential neighbourhoods come next with $10 \%$ of all answers mentioned by 
$20 \%$ of respondents, mostly women or parents with children. Cultural or historical walking circuits come last with a total of $8 \%$ of all answers mentioned by $17 \%$ of respondents, mostly educated women owning a car. This poor result underlines how different citizen needs are from the tourist's, and shows that traditional circuits are not in tune with an indigenous perception of the city. Thus a real need to innovate arises, giving way to new approaches of walking promotion more respectful of proximity needs. Almost half of the respondents (48\%) prefer to compose their own itinerary as they go, on the spur of the moment. While round circuits are quite a success $(39 \%)$, linear paths are only chosen by a little more than a person out of ten (12\%). People, especially women, also tend to combine several existing itineraries $(25 \%)$, or choose a path because it's useful to link places where they perform their daily activities (17\%). Car ownership and availability, higher income and the presence of children all influence route choice in favour of round circuits or the combination of different circuits, rather than linear circuits. It seems therefore essential, when designing and promoting walking circuits, to inspire and suggest, rather than dictate; to take into account real walking patterns, rather than trying to impose a set pattern; and to include a bouquet of the shortest routes to a series of important destinations, as well as a set of alternative routes for the return trip, rather than trying to bring every possible destination within a single linear route. Ultimately a complete walking network should be provided that optimises route choice while bestowing the largest possible degree of freedom to the user. It then becomes more a matter of providing him with the right representation tools to cope with this network. We are currently working on devising such a tool through the development of a web interface that serves as a personal multimodal itinerary choice calculator.

\subsection{How does walking become a habit?}

Many people walk quite often along the same routes, and it is in fact a habit for $60 \%$ of the respondents. One out of four goes for a walk from time to time, one out of ten less often, and only one out of twenty reported being there for the first time. People seem to walk just as frequently when they always have a car available as when they never do, while occasional car users do show a greater tendency to walk occasionally than those who are captive of either the automobile or public transport. People that walk in residential districts and along natural sites tend to know the premises well, while the city centre concentrates most tourists and infrequent users. No matter how old, habitués are always the most important category of users for any given place, always representing more than half of all users. Familiarity however does increase with age, older people being amidst the most frequent users. Familiarity also increases if people dispose of more time to walk, as shown by the fact that $78 \%$ of unemployed, $71 \%$ of retired elders, $67 \%$ of housewives and $55 \%$ of part-time employees claim they are habitués, vs. only $53 \%$ of full-time employees, $50 \%$ of students and $46 \%$ of independents. Widows, divorced and single parents tend to visit a place much more often than couples. Young people who are still single, on the other hand, tend mostly to be only occasional users. The presence of children doesn't seem 
to influence walking frequency patterns, except when wanting to explore new ground. People with children tend to remain on familiar premises closer to home. Likewise, car availability doesn't influence walking frequency patterns much, except it does allow for greater freedom to explore new places: those who come to a new place for the first time are twice more likely to have the use of a car. Car ownership, on the other hand, does influence walking frequency in a somewhat paradoxical manner, since people who do not own a car have a tendency to walk less often than those who do (35\% vs. 50\%). This result can be partially explained by the larger number and greater length of walking trips during weekends, when leisure mobility trends are still very much intertwined with the use of the car to gain access to the leisure sites where people actually start walking. To curb this trend, substantial efforts must be made in terms of leisure site accessibility by public transport and human-powered means.

\subsection{Do people keep walking over the years?}

$48 \%$ of respondents declare their walking practices have remained constant over the last five years, and $42 \%$ declare that their practice of walking has actually increased. Among these, a certain number quote the arrival of a child or the acquisition of a dog as a determining factor. Only 10\% indicate having decreased their time devoted to walking, primarily for reasons linked with health or great age issues.

\subsection{Hebdomad walking rhythms}

People do not seem to have a special day for walking purposes. One out of three usually walks everyday, one out of four mostly on weekdays and one out of six either on Saturday or Sunday. Women tend to walk everyday of the week $(36 \%$ vs. $30 \%$ ), in particular on Saturdays (18\% vs. $15 \%)$, whereas men tend to walk slightly more on weekdays $(25 \%$ vs. $21 \%)$ or not to walk downtown at all $(19 \%$ vs. $15 \%$ ). On the other hand there is no gender difference regarding Sunday walks (15\%). $40 \%$ of everyday walkers are seniors, while a third are active adults and teenagers represent only a quarter of this category. Seniors experience a severe drop in walking patterns on weekends (5\% on Saturdays and $7 \%$ on Sundays, vs. an average of $16 \%$ for other age groups on both these days), while teenagers privilege Saturday walking tours (30\%), mostly for shopping and meeting friends. People who do not have children feel freer to walk everyday, while weekends are much preferred by families with children. People who have no vehicle available definitely tend to walk more everyday (39\% vs. $27 \%)$, while people who have a vehicle at their disposal prefer walking during weekdays ( $25 \%$ vs. $16 \%$ ), whereas on weekends there seems to be no difference due to car availability. Walking assiduity diminishes as the number of cars increases within a household (37\% of people without a car declare to walk everyday, vs. $33 \%$ of those who have a car and only $26 \%$ of those who have two cars). The total time devoted to weekly walking displacements nevertheless does not vary much, because walks on weekdays are generally shorter than on weekends, and people that have two cars walk more during the weekend $(23 \%$ vs. $15 \%$ on average for 
other categories on Saturdays; $21 \%$ vs. $13 \%$ on average for other categories on Sundays).

\subsection{Circadian walking rhythms}

The preferred period of the day to enjoy a stroll is by far in the afternoon $(60 \%)$. A person out of five declares to walk any time $(22 \%)$, one out of six in the mornings $(16 \%)$, and roughly one out of ten prefer evenings $(11 \%)$. There are important gender and age differences. Men prefer to walk in the evening $(15 \%$ vs. $9 \%$ ) and in the early morning (5\% vs. $2 \%$ ), whereas women opt rather clearly for the afternoon (66\% vs. 52\%). Older adults and seniors walk mostly in the morning and only very seldom in the evening. People who have children are more numerous to walk in the afternoon ( $66 \%$ vs. $58 \%$ of those who don't).

\subsection{How long do people have for a walk?}

Time for a walk is usually rather short, and only a few people walk longer distances. $75 \%$ of the respondents walk for less than an hour at a time. Of these, one out of three walks between 15 and 30 minutes, while only one out of five walks between 45 minutes and 1 hour. After this limit frequencies decrease sharply, with only one out of ten walking between 1 and $1 \frac{1}{2}$ hours or between 1 $1 / 2$ and 2 hours, and only one out of twenty walking for more than two hours. Time is thus an important limiting factor in walking choices and relatively short yet attractive circuits would have a better chance to be adopted by potential walkers. Shorter circuits include parks and playgrounds near dwellings or district centres boasting a strong concentration of commercial venues, services and public transport interfaces. Longer circuits tend to follow waterways or go across more natural areas. They can also be due to the larger influence radius of major attractors.

Women tend to go for shorter walks than men, and the older the person, the longer she walks. $75 \%$ of long walk adepts are retired, while a person out of three that walks mostly on short transit trips is a student. People working fulltime tend to walk longer than people who work part-time, though these two categories both account for a fifth of short transit trips. People who have children are twice more likely to walk between around 1 hour, while people who don't are four times more likely to go for short transit trips. Single parents tend to go for either rather short or quite long walks (over 2 hours). People who do not use the car walk much longer than those who do, while the latter are twice more likely to go on short transit trips. The more cars a household owns, the less time those who live in it tend to walk.

\section{How effectively do public policies promote walking?}

Though roughly a third of the respondents declare being acquainted with published maps depicting the proposed walking routes, these seem to have relatively little influence on walking practices, influencing positively only $12 \%$ of respondents, the very ones which have in fact actually used the maps. Families 
are twice more likely to use them, as are $28 \%$ of newcomers and first-timers visiting a given place. Tourists and people unfamiliar with the location do happen to be the most likely targets. The more one walks, the less one seems likely to be influenced by these walking routes. These figures, though far from the maps' true potential, do show how important readily available information can be in order to convince potential walkers to explore new territories for the first time.

The Town of Geneva devised a symbol to enhance visual coherence among the diverse Pedestrian Masterplan communication tools, in the form a little green "P"-shaped man people may alternatively see on sidewalks and publicity billboards as well as on the maps themselves and the Pedestrian Masterplan website. A third of the respondents had never seen this symbol, especially seniors ( $45 \%$ have never seen it, vs. $32 \%$ on average for other age groups). A quarter of the respondents had already seen it on a sidewalk and a fifth recall seeing it but can't remember in which context. Though frequent walkers are more likely to have come across this symbol, this has by no means an influence regarding how knowledgeable a person may be of the proposed walking routes. Approximately the same number of people has seen the symbol on maps $(13 \%)$ or billboards (12\%). Only $2.1 \%$ have visited the website, but this small percentage does include almost every surveyed tourist, emphasizing how important it is to make that kind of information available online for tourism purposes.

A good measure of effectiveness in targeting specific groups consists in asking people whom they feel is being aimed at by the communication campaign tools. Half of the users, and women in particular, estimate that the maps promoting the walking circuits address to everyone. $30 \%$ of the respondents, primarily young people, estimate these maps are solely intended for tourists. $15 \%$ of the respondents, on the other hand, think they are primarily intended for the inhabitants. Overall a great number of people regret the lack of dissemination of these maps and estimate they deserve to be more widely broadcasted. The tourist office is the first logical choice people have selected (46\%). Touristaimed locations and infrastructure such as hotels and restaurants collect $16 \%$ of all votes, and trendy places $4 \%$. Transit places collect $60 \%$ of all votes, $40 \%$ of which for the airport and train station and 20\% for local public transport counters, bus stops and display units inside the buses themselves. Proximity favourite places where people go for daily activities gather the second largest bulk vote: upfront come kiosks and tobacco selling shops (38\%), food stores and shopping centres come second (35\%), the post office comes third (31\%), schools come fourth (9\%) and libraries and social venues come fifth (7\%). Public services collectively gather a quarter of the votes $(25 \%)$, shared between rather visible services as the police or the town hall (14\%) or the municipal information office (8\%). Placing the maps directly at walking range is also frequently suggested, the walking route itself being the obvious choice for $9 \%$ of the respondents, whereas $7 \%$ suggest a system of street distribution boxes similar to that of newspapers, namely in parks and important crossroads. Culture is also mentioned as a point of entry with some potential. Cultural services and ticketing 
offices gather $7 \%$ of votes, while map handouts during festivals and other large demonstrations is encouraged by $5 \%$ of the respondents. Household mailings are suggested by $8 \%$ of the respondents. Some people suggest specifically targeting users of other means of transport, for example through bicycle hiring spots $(3 \%)$ or gas stations and automobile clubs $(2 \%)$. Other places mentioned included places related with health (hospitals, medical cabinets, pharmacies, etc), with sports (sport centres, swimming pools, fitness centres, etc), with senior-related services (EMS, centres for senior activities, senior clubs, etc), with children (schools, nurseries, etc), with young people (leisure clubs, meeting places, etc) and finally with dogs (dog parks, the caninettes, etc). A distribution within private companies was also suggested, which could be interesting within the framework of a mobility management process, provided the company location is near a walking route.

\section{The walkers' onsite evaluation}

The respondents had to appreciate the specific site where they were being interviewed according to six different criteria: lighting, texture, route choice, urban furniture, nature \& landscape and historical urban value. $60 \%$ of the respondents regard the site on the whole as a success, and only $7 \%$ consider it bad or insufficient. $31 \%$, however, allot the minimum passing grade, thus showing a certain dissatisfaction with one or the other of the specific criteria of evaluation. Lighting receives the most mitigated evaluation, with $32 \%$ of rather negative grades, $25 \%$ of average grades and again $33 \%$ of rather positive grades. Natural sites tend to be considered as especially under-equipped in this respect, while strong transit nodes gathered the best reviews. Texture is one of the most positively rated criteria, getting a positive grade from $60 \%$ of respondents. Route choice is the most positive evaluation by far, with close $80 \%$ positive marks. People did give a bad mark to a particular black spot that had already been previously identified by the City Planning Office, thus confirming this diagnostic and the urgent need to redesign this particular route. Urban furniture causes an overall rather positive appreciation though more mitigated than other evaluations. Thus only $54 \%$ of respondents consider that it is successful vs. $46 \%$ who don't. $66 \%$ of respondents find that both nature and landscape are enhanced in a majority of sites, and $31 \%$ even rate maximum grades to this set of criteria, while negatives grades are only given by $15 \%$ of respondents. Historical value is considered successfully managed by $45 \%$ of respondents, while a quarter think one could do better in this field and $10 \%$ actually allot a rather bad mark.

$62 \%$ of walkers enjoy the proximity of nature or the presence of greenery. Peace and quiet are a must for $36 \%$ of them, and a further $14 \%$ quote a particular place where they like to relax. $25 \%$ of respondents mention the presence of water as an attractivity factor, while $17 \%$ mention the landscape as the main attraction. $14 \%$ congratulate the route choice. A person out of ten mentions sociability factors.

$64 \%$ of respondents advances proposals in order to improve pedestrian signing: signposts $(37 \%)$, ground marks $(16 \%)$ and route maps posted at 
strategic crossroads (12\%). 32\% of the users also claim measures to improve the visibility of park entry and exit points, and $25 \%$ suggest facilitating pedestrian and cycling access to the sites.

\section{Walking is an inside job}

From these results we may point out that there is more to walking promotion than meets the eye. It is not enough to plan walking routes, draw maps on paper and stack these at the nearest tourist office. Indigenous walkers expect a whole range of diffusion places, much broader and much nearer to their daily activities, as they usually anchor these walking routes to their daily agendas. Furthermore, users adhere to walking much more strongly when route accessibility, security and attractivity are guaranteed. Although walking for walk's sake is quite possible, more often than not opportunities for walking are motivated by transit motives and the combination of several other activities besides the leisurely stroll itself. The more walking routes adapt to other reasons for people being there the more they are invested. A successful walking route tends to dissolve against a wider background made up of high-quality urban fabrics that can effectively lodge the multifonctionnality required by users' daily practices and respond to multilayered users' representations. Ideally public places along this route evolve into hybrid places capable of hosting leisure motives as well as more utilitarian needs, while these tend to reinforce each other though revolving on different circadian and hebdomad rhythms. Walking settings are more than functional, they are emotional: they provide us with places to grow and to remember, places sit back and relax and enjoy life, places to meet people that we care about, places to fall in love with. Long before becoming an act, walking is first and foremost a social construct. Thus my last and possibly only piece of advice is that before we start building walk-friendly routes, we should devise better ways to start designing walk-friendly minds.

\section{References}

[1] Dewarrat, J.-P., Quincerot R., Weil M., Woeffray B., Paysages Ordinaries: De La Protection Au Projet, Sprimont, Belgique, Pierre Mardaga, 2003.

[2] Grosjean, M., Thibaud J.-P., (Dir.), L'espace Urbain En Méthodes, Marseille, Parenthèses, 2001.

[3] Thibaud, J.-P., (Dir.), Regards En Action. Ethnométhodologie Des Espaces Publics, Grenoble, A La Croisée, 2002.

[4] Toussaint Jean-Yves, Zimmermann Monique (Dir.), User, Observer, Programmer Et Fabriquer L'espace Public, Lausanne, PPUR, 2001. 